\title{
Comparative reproductive biology of the six species of Rhododendron (Ericaceae) in Hong Kong, South China
}

\author{
Sai-chit Ng and Richard T. Corlett
}

\begin{abstract}
Six rhododendron species grow wild in Hong Kong: Rhododendron farrerae Tate and Rhododendron simsii Planch. are common and widespread, Rhododendron moulmainense Hook. f. is restricted, and Rhododendron championiae Hook. f., Rhododendron hongkongense Hutch., and Rhododendron simiarum Hance are rare. The length and timing of the flowering period varied between species, but peak flowering for all was between late February and early May, when weather is variable and unpredictable. All species were more or less self-sterile, had sucrosedominated nectar, and were visited by diverse insects, of which Apis cerana, Bombus eximius, and Xylocopa spp. are the major pollinators. Seeds of all species, except $R$. simiarum, had a light requirement for germination. There were large differences between species in the pollen/ovule ratio (176-1343), daily nectar production $(0.9-38.7 \mu \mathrm{L}$ per flower), large bee visits $(0.35-4.28$ per flower per $100 \mathrm{~h})$ and total visits $(0.92-14.53)$, mean seed production per flower (2-135) and per plant (100-14800), and mean seed weight (0.11-0.45 mg). The large-bee visitation rate was significantly correlated across species with mean daily nectar production and mean seed set. The two common species had the smallest flowers, lowest nectar production, lowest pollen/ovule ratios, fewest large bee visitors, and produced fewest seeds.
\end{abstract}

Key words: breeding system, China, pollination, rarity, Rhododendron, seeds.

Résumé : Il y a six espèces de rhodendron qui pousse à l'état sauvage à Hong-Kong: le Rhododendron farrerae Tate et le Rhododendron simsii Planch. sont communs et répandus, le Rhododendron moulmainense Hook. f. est restreint, et les Rhododendron championiae Hook. f., Rhododendron hongkongense Hutch. et Rhododendron simiarum Hance sont rares. La longeur et le moment de la période de floraison varient selon les espèces mais atteignent un sommet, chez toutes les espèces, entre la fin de février et le début de mai, période où la température est variable et imprévisible. Toutes les espèces sont plus ou moins auto-stériles, produisent un nectar dominé par le sucrose et sont visitées par divers insectes parmi lesquelles les Apis cerana, Bombus eximius et Xylocopa spp. sont les pollinisateurs principaux. Les graines de toutes les espèces, sauf celles du $R$. simiarum, ont besoin de lumière pour germer. Il y a de grandes différences entre les espèces dans le rapport pollen/ovule (176-1343), dans la production quotidienne de nectar $(0,9-$ $38,7 \mu \mathrm{L}$ par fleur), dans le nombre de visites par de grosses abeilles $(0,35-4,28$ par fleur par $100 \mathrm{~h})$ et le nombre total de visites $(0,92-14,53)$, dans le nombre moyen de graines produites par fleur (2-135) et par plante $(100-14800)$, et dans le poids moyen des graines $(0,11-0,45 \mathrm{mg})$. Le taux de visite par les grosses abeilles montre une corrélation significative parmi les espèces avec la production quotidienne moyenne de nectar et le nombre moyen de graines formées. Les deux espèces les plus communes ont les fleurs les plus petites, la production de nectar la plus faible, les plus faibles rapports pollen/ovule, le plus petit nombre de visites par les grosses abeilles, et produisent le moins de graines.

Mots clés : système de croisement, Chine, pollinisation, rareté, Rhododendron, graines.

[Traduit par la Rédaction]

\section{Introduction}

The reproductive biology of the large and successful woody plant genus Rhododendron has some unusual features. The flowers have a combination of apically porose anthers and strongly adhesive pollen, which has not been

Received May 4, 1999.

S.-C. Ng and R.T. Corlett. ${ }^{1}$ Department of Ecology and Biodiversity, University of Hong Kong, Pokfulam Road, Hong Kong.

${ }^{1}$ Author to whom all correspondence should be addressed (e-mail: corlett@hkucc.hku.hk). reported elsewhere (King and Buchmann 1995) and which, together with the large flower size and widely spaced stamens, must restrict the range of potential pollinators. Although a wide range of flower visitors have been reported, the most common major pollinators outside the tropics appear to be bumblebees (Buchmann 1983; Yumoto 1987, 1988; Kudo 1993; Escaravage et al. 1997). There have been no detailed studies of the pollination of tropical species, but casual observations and deductions from floral traits suggest a wider range of pollinators, including birds (Nectariniidae, Meliphagidae, and Zosteropidae), hawkmoths (Sphingidae), butterflies, and bees (Stevens 1976; Kjellsson et al. 1985). The production of numerous, tiny wind-dispersed seeds is also unusual for long-lived woody plant species, particularly 
in the tropics. This provides a great reproductive potential, but successful establishment from seed requires favourable microsites (Cross 1981; Plocher and Carvell 1987; Kohyama and Grubb 1994) and seedling recruitment is rare in some Rhododendron species (Pornon and Doche 1995).

Despite the ecological and economic importance of the genus, and the unusual aspects of its reproductive biology, detailed field studies of reproduction have only been done for a few species (Cooper and McGraw 1988; Kudo 1993; Pornon et al. 1997; Escaravage et al. 1997) while earlier studies were mostly carried out in gardens (e.g., Yamaguchi 1980; Williams et al. 1984, 1991; Padrutt et al. 1992). This paper reports a study of the six Rhododendron species that are native to Hong Kong $\left(22^{\circ} \mathrm{N}, 114^{\circ} \mathrm{E}\right)$, China ( $\left.\mathrm{Ng} 1999\right)$. These represent three of the eight subgenera of Rhododendron (Chamberlain et al. 1996) and differ in maximum height, floral characteristics, and both local and regional abundance. Rhododendron farrerae Tate and Rhododendron simsii Planch. (both in subgenus Tsutsusi) are low shrubs $(0.5-1.5 \mathrm{~m})$, that are common in fire-maintained shrubland and grassland. Rhododendron championiae Hook. f., Rhododendron hongkongense Hutch., Rhododendron moulmainense Hook. f. (subgenus Azaleastrum), and Rhododendron simiarum Hance (subgenus Hymenanthes) are tall shrubs and small trees $(1-8 \mathrm{~m})$, that are relatively rare in Hong Kong and are restricted to forest and tall shrubland on steep hillsides protected from fire. The relative abundance of the six species in Hong Kong is in the order: $R$. simsii $>R$. farrerae $>R$. moulmainense $>R$. hongkongense $>R$. simiarum $>$ $R$. championiae. Rhododendron hongkongense is globally rare and has only been recorded from three sites outside Hong Kong. The coexistence of six species provides an opportunity to identify which features of the reproductive strategy are constant and which ones vary between species. A comparison between the reproductive biology of the rare and common species may also help to understand the causes and consequences of their rarity and thus contribute to the development of management strategies for their conservation (Kunin and Gaston 1993; Kunin and Shmida 1997). The objectives of this study were, therefore, (i) to compare the reproductive phenology and the flower, fruit, and seed characteristics of the six species; (ii) to identify potential pollinators and to compare visitation rates; and (iii) to identify the breeding systems and measure fruiting success.

\section{Materials and methods}

\section{Study area}

Hong Kong $\left(22^{\circ} \mathrm{N}, 114^{\circ} \mathrm{E}\right)$ is situated on the south coast of China and consists of a section of the mainland (the New Territories) and several islands, the largest of which is Lantau Island. The climate is subtropical, with a hot, wet summer and cool, dry winter, during which frosts may occur above $400 \mathrm{~m}$ altitude (Dudgeon and Corlett 1994). The original vegetation of the Hong Kong region must have been evergreen or semi-evergreen forest, but this has been largely cleared within the last 3000 years, with most clearance probably in the last 1000 years. More than $80 \%$ of the total land area of $1100 \mathrm{~km}^{2}$ has a rugged topography and is covered in secondary grasslands and shrublands, maintained by anthropogenic fires, with a small but increasing area of secondary forests, which have largely developed since 1945 (Zhuang and Corlett 1997). Some patches of forest at high altitude seem to have escaped complete clearance and support an exceptionally diverse flora. The main study site, Ma On Shan in the New Territories, is an irregular ridge (350-650 m above sea-level) formed of heterogeneous volcanic tuffs, with thin soil, large areas of exposed rock, and unstable, steep to precipitous sides. Forest and tall shrubland with many locally rare species covers much of the northern slopes, while the more gentle southern slopes are largely fire-maintained low shrubland and grassland. All six Rhododendron species occur at this site, with $R$. farrerae and $R$. simsii scattered in the low shrubland, while the other species are confined to the forest, forest edge, and tall shrubland. Most of the pollinator observations and bagging experiments for the six species were carried out at this site, except for $R$. championiae, for which most observations and experiments were carried out at Tai $\mathrm{O}(50-100 \mathrm{~m})$ on Lantau Island, where it is more abundant. Some additional observations for $R$. hongkongense were made at Pat Sin Leng (Bride's Pool) (100$150 \mathrm{~m}$ ) in the northern New Territories. The three study sites are within $45 \mathrm{~km}$ of each other.

\section{Floral phenology and other traits}

The reproductive phenology (onset and end of the flowering season, peak flowering period, and fruiting period) of all six species at the main study site (Ma On Shan) was assessed from numerous visits made in 1996 and 1997. The shapes, maximum diameters, and depths of the corolla of 12-24 fully opened flowers were measured, and flower colors were described using Kornerup and Wanscher (1978). The timing of anthesis was noted in the field, and stigma receptivity was assessed using $3 \%$ hydrogen peroxide solution and confirmed by hand crossing. Floral longevity was examined in 1996 by labeling flower buds just before they opened and observing them once every 2 days until the corolla wilted or detached. Nectar volumes were measured in 1997 by enclosing 211 flower buds from two to seven flowering individuals in plastic bags just before they opened, to exclude visitors and prevent evaporation. The volume was measured every day between 8:00 and 11:00 a.m., with a capillary tube of known internal diameter, until the corolla completely wilted or detached. The capillary tubes containing nectar were stored at $-20^{\circ} \mathrm{C}$ until analysis by HPLC to determine the relative proportions of sucrose, glucose, and fructose.

Pollen/ovule ratios were estimated for one or two flower buds from four to six haphazardly selected individuals of each species. The flower buds were collected before their anthers dehisced and were preserved in $70 \%$ alcohol. Ovules were counted by dissecting under a stereo-microscope. All anthers (5 or 10 depending on the species) in each flower were submerged in $500 \mu \mathrm{L}$ of $10 \mathrm{M}$ sodium hydroxide solution, completely macerated with a pair of extra fine forceps, mixed thoroughly with a vortex mixer, and left for $24 \mathrm{~h}$. Then $500 \mu \mathrm{L}$ of a solution containing $40 \% \mathrm{v} / \mathrm{v}$ glycerol and $40 \%$ w/v sucrose was added and mixed thoroughly. An aliquot of $5 \mu \mathrm{L}$ was then transferred to a haemocytometer, and the number of pollen tetrads was counted.

\section{Flower visitation}

Visits by potential pollinators were observed casually throughout the study and systematically on several calm and clear days. A large individual flowering plant was observed for $20 \mathrm{~min}$, and the number and types of visitors and the number of flowers opened on the plant were recorded. Only visitors that attempted to collect nectar and (or) pollen were recorded. Most observations in 1996 were made between 9:30 a.m. and 3:30 p.m., while in 1997, both day and night observations were made on all six species. Most visitors were collected and identified to the species, where possible, except for Diptera and Coleoptera.

\section{Breeding system}

The breeding system was investigated on 10-15 individuals of each species in 1996 and 1997. For each individual, three to six flowering branches or inflorescences, each with 2-10 unopened 
flowers, were labeled and enclosed in nylon mesh bags, and each of them was treated as an independent experimental unit. After the flowers opened, each of three treatments was applied to one to three experimental units on each tree, which then remained bagged until late October. In the bagging treatment (Tr. B), the flowers were bagged to test for spontaneous autogamy; in the hand-selfing treatment (Tr. S), the flowers were hand-pollinated with self-pollen to test for self-fertility; and in the hand-crossing treatment (Tr. C), they were hand-pollinated with pollen from another individual at least $10 \mathrm{~m}$ away. Another one to four unbagged flowering branches on the treated individuals were labeled to measure fruit and seed set rate under open pollination (Tr. O). Because fruit and seed set under open pollination were very low, the sample size for this treatment was increased by including the results from the 30-70 plants of each species used for the reproductive performance study described below. The numbers of fruits produced in each labeled unit were counted in July. Fruits were harvested in late October, and seeds were counted. Seed set per flower and percentage fruit set were compared among treatments using ANOVA on ranks and discriminated by Dunn's test. As the species have different numbers of ovules, the percentage seed set $(100 \times$ seed number per flower/mean number of ovules per flower) was used to compare among species. For each species, the self-compatibility index ( $\mathrm{SCI}=$ seed set after selfing/seed set after crossing) was calculated according to Lloyd and Schoen (1992). The reproductive performances of the six species were compared in 1997 by recording the proportion of plants flowering, the number of flowers on each plant, and the number of seeds produced by each plant, for 30-70 labeled, mature individuals of each species on Ma On Shan or, for $R$. championiae, at Tai $\mathrm{O}$.

\section{Seed germination and other characteristics}

Seeds from open pollination, after storage in the dark at $17-20^{\circ} \mathrm{C}$ for $2-3$ months, were used in germination trials. Seeds collected in November 1995 were germinated on soil in 1996, while those collected in 1997 were germinated on sterile 1\% agar in 1998. A dark treatment was added to the germination trial in 1998, with the agar plates enclosed in aluminum foil. The germination trials were repeated in 1999 using the same lot of seeds, which had been stored for 14 15 months. Seed shape, size, and mass were measured, and the wing loadings were calculated by dividing the weight by the maximum cross-sectional area, which was estimated by assuming the seeds all had an elliptical cross-section. The terminal velocity in still air was measured for each species using a stopwatch.

\section{Results}

\section{Phenology}

The length and timing of the flowering period varied between species and sites (Fig. 1). Rhododendron simsii and $R$. farrerae had the longest flowering periods, and $R$. simiarum had the shortest and most synchronous. Although the flowering periods for all species in Hong Kong as a whole overlapped, this was not true within the main study site (Ma On Shan). The peak flowering season for all species occurred within the period between late February and early May when Hong Kong's weather is very variable and unpredictable. Variation in flowering phenology between sites was particularly obvious for $R$. championiae, where the Tai $O$ population began to flower almost 1 month earlier than the populations at Ma On Shan and on Hong Kong Island. Phenological patterns were very similar in the 2 years
Fig. 1. Flowering phenology of the six Rhododendron species in 1996 and 1997. The horizontal line represents the period over which the flowers could be found somewhere in Hong Kong; the square brackets show the flowering season of the six species at the main study site (Ma On Shan); and the curved brackets show the peak flowering period.

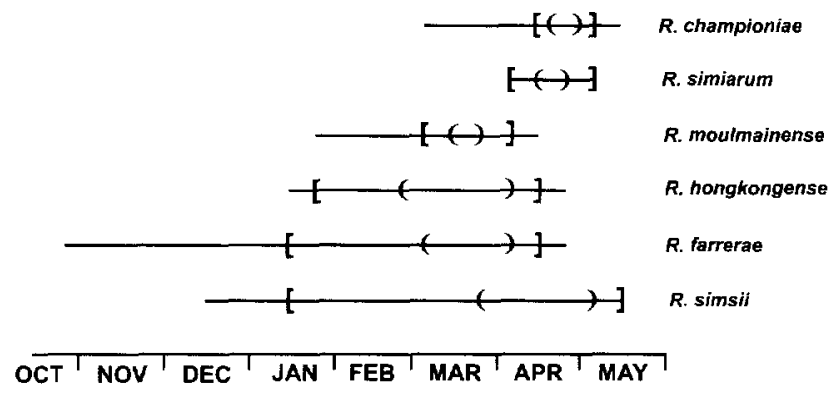

of detailed observations, 1996 and 1997, but casual observations suggest large differences between years can occur. Rhododendron moulmainense started flowering 6 weeks earlier in 1995, while $R$. simiarum and $R$. hongkongense produced far fewer flowers in 1998 and 1999 than in 19961997. Fruits of all six species ripened and burst open between late October and early December, which is the driest and windiest period of the year.

\section{Floral traits}

Rhododendron farrerae and $R$. hongkongense produce single-flowered inflorescences, those of $R$. simsii have 1 or 2 flowers, while those of $R$. championiae, $R$. moulmainense, and $R$. simiarum have up to 4,6 , and 10 flowers, respectively. Rhododendron championiae, $R$. hongkongense, and $R$. simsii produce multiple inflorescences per branch, while $R$. farrerae, $R$. moulmainense, and $R$. simiarum usually produce one. Rhododendron championiae has the largest flowers, and $R$. farrerae has the smallest (Table 1). With the exception of $R$. hongkongense and $R$. simiarum, which have flat saucer-shaped and bell-shaped corollas, respectively, all species studied have a funnel-shaped corolla that becomes narrower at the base. Corollas of $R$. farrerae and $R$. simsii are brightly colored (purplish pink and red, respectively), whereas the other four species have pale colors (pink for $R$. moulmainense, pink to white for $R$. simiarum, and white for $R$. championiae and $R$. hongkongense). All species have brightly colored markings (magenta to yellow dots) on the inner face of the uppermost petals. The flowers of $R$. championiae, $R$. moulmainense, $R$. simiarum, and $R$. hongkongense have a strong, sweet scent. The scent is much weaker in $R$. simsii and is almost undetectable to humans in $R$. farrerae. The longevity of flowers varied from less than 3 days in $R$. moulmainense and $R$. championiae to 6 days in $R$. simiarum (Table 1).

Pollen tetrads are borne on viscin threads, and both of them are highly adhesive. Pollen-loaded viscin could be easily expelled from the anthers by vibrations caused by movements of flower visitors and strong winds. The anthers mature before the flowers open, so pollen tetrads were occasionally seen inside unopened flowers. The stigmatic surface was isolated from the anthers by the petals until the flowers were fully opened, but stigmatic grooves began to secrete sticky exudates, and the stigmas gave positive results with 
Table 1. Flower size and longevity, nectar production and composition, pollen and ovule counts, and reproductive performance under open-pollination in 1997, for the six Rhododendron species.

\begin{tabular}{|c|c|c|c|c|c|c|}
\hline & R. championiae & R. farrerae & R. hongkongense & R. moulmainense & $R$. simiarum & R. simsii \\
\hline \multicolumn{7}{|l|}{ Flower size } \\
\hline$n$ & 12 & 26 & 15 & 22 & 24 & 24 \\
\hline Diameter $(\mathrm{mm})$ & 91 & 27 & 56 & 68 & 53 & 42 \\
\hline Depth $(\mathrm{mm})$ & 46 & 18 & 19 & 38 & 33 & 31 \\
\hline Flower longevity (days) & $2.8(0.4)$ & $3.3(0.3)$ & $4.9(0.3)$ & $2.8(0.1)$ & $6.0(0.1)$ & $5.2(0.1)$ \\
\hline \multicolumn{7}{|l|}{ Nectar production } \\
\hline$n$ & 10 & 35 & 36 & 27 & 31 & 44 \\
\hline Daily production $(\mu \mathrm{L})$ & $14.3(2.6)$ & $0.8(0.1)$ & $5.8(0.5)$ & $8.4(0.9)$ & $38.7(2.5)$ & $0.9(0.1)$ \\
\hline Total production $(\mu \mathrm{L})$ & $43.2(6.6)$ & $1.7(0.4)$ & $20.8(2.1)$ & $14.4(1.7)$ & $202.7(12.8)$ & $1.5(0.3)$ \\
\hline \multicolumn{7}{|l|}{ Nectar composition (\%) } \\
\hline$n$ & 4 & 6 & 4 & 3 & 5 & 4 \\
\hline Sucrose & $93(3.2)$ & $94(1.6)$ & $99(0.2)$ & $98(0.3)$ & $100(0.1)$ & $79(6.7)$ \\
\hline Glucose & $4(1.5)$ & $4(1.1)$ & $0(0.0)$ & $1(0.3)$ & $0(0.1)$ & $11(3.3)$ \\
\hline Fructose & $3(1.7)$ & $2(1.1)$ & $1(0.2)$ & $1(0.2)$ & $0(0.0)$ & $10(3.4)$ \\
\hline \multicolumn{7}{|l|}{ Pollen or ovule number } \\
\hline$n$ & 3 & 5 & 5 & 5 & 5 & 6 \\
\hline Pollen $\left(\times 10^{3}\right)^{*}$ & $256(45)$ & $106(21)$ & $229(16)$ & $573(94)$ & $344(23)$ & $155(14)$ \\
\hline Ovule & $1392(60)$ & $581(20)$ & $801(40)$ & $1849(124)$ & $267(27)$ & $898(93)$ \\
\hline Pollen/ovule ratio & $184(31)$ & $179(33)$ & $284(13)$ & $306(40)$ & $1343(167)$ & $176(14)$ \\
\hline \multicolumn{7}{|l|}{ Reproductive performance } \\
\hline$n$ & 72 & 37 & 40 & 39 & 37 & 43 \\
\hline Flowers per plant & $40.9(14.4)$ & $49.5(18.1)$ & $46.7(18.0)$ & $164.4(41.1)$ & $50.6(13.8)$ & $84.6(25.4)$ \\
\hline$\%$ plants flowering & 51.1 & 77.1 & 55.0 & 66.7 & 67.6 & 95.3 \\
\hline Estimated seeds per plant ${ }^{\dagger}$ & 3594 & 94 & 4992 & 14769 & 4840 & 169 \\
\hline
\end{tabular}

Note: Numbers in parentheses are standard errors.

*Number of pollen tetrads multiplied by four.

${ }^{\dagger}$ Mean number of flowers per plant multiplied by the mean seed set per flower under open-pollination (Table 3).

hydrogen peroxide at least 3 days before the flowers opened. Hand-crossing to the stigma of unopened flowers resulted in full seed set, showing that the stigma is already fully receptive at this stage. The pollen/ovule ratio ranged from 176 in $R$. simsii to 1343 in $R$. simiarum (Table 1). Nectar production varied over two orders of magnitude between species, with $R$. simiarum producing the largest amount of nectar and $R$. simsii the least. All nectars were sucrose dominated, with the sucrose making up more than $90 \%$ of the major soluble carbohydrates in all species, except $R$. simsii (Table 1).

\section{Flower visitation}

Potential pollinators seen visiting the flowers during daylight hours were in four orders of insects (Hymenoptera, Lepidoptera, Coleoptera, and Diptera) plus the Fork-tailed Sunbird (Aethopyga christinae) (Table 2). Hymenoptera were the major visitors to all six species and Apis cerana, Bombus eximius, and Xylocopa spp. (X. irridepennis, X. phalothorax, and $X$. dejeanii) were the most abundant bees, visiting many flowers in a short time and vigorously collecting nectar and pollen. Bombus eximius and Xylocopa spp. were probably the most effective pollinators, because their large sizes (1.8-2.7 cm in body length) ensured contact with both the anthers and stigma and their bodies were usually covered in pollen. Although Bombus eximius was an important visitor for most species, it was only seen at the Ma On Shan and Pat Sin Leng sites and was absent from Tai $O$ and most other parts of Hong Kong. Apis cerana $(1.0-1.2 \mathrm{~cm})$ usually bypassed the anthers and stigma when collecting nectar be- cause of its small size. However, it also actively collected pollen by clinging to the anthers and sometimes contacted the stigma during such visits. Wasps, mainly Vespa species, only visited occasionally and briefly to collect nectar. Dayflying hawkmoths (Sphingidae), including Cephonodes hylas, Satapes infernalis, S. tagalica, and Macroglossum spp., hovered over flowers as they collected nectar and occasionally contacted the anthers and stigma of only $R$. championiae and $R$. moulmainense, which have the longest stamens and styles. Butterflies, including Delias pasithoe, Kaniska canace, Papilio spp., and Hebomoia glaucippe, perched on the sides of the corolla and seldom touched the anthers or stigma. Syrphid flies and an unknown bee were too small $(<0.5 \mathrm{~cm}$ length) to effectively pollinate rhododendron flowers. Other dipteran visitors collected nectar without contacting the anthers and stigma. Beetles (mainly Melyridae and Scarabaeidae) usually fed on floral parts and rarely moved between flowers. Fork-tailed Sunbirds were rare visitors to flowers of $R$. championiae, $R$. hongkongense, $R$. moulmainense, and $R$. simiarum and were not seen contacting the anthers and stigma.

The diversity and abundance of visitors were low early in the flowering season (January to late March), when the weather was cool, windy, and frequently misty, and visits were dominated by Apis cerana and Bombus eximius. As the weather became warmer and more sunny after late March, more Xylocopa spp. and lepidopteran visitors were seen. Flower visitors were much rarer at night and were mainly lepidopterans, including hawkmoths (Sphingidae) and noc- 
Table 2. Number of visits per flower per $100 \mathrm{~h}$ to the six rhododendrons in 1996 and 1997.

\begin{tabular}{|c|c|c|c|c|c|c|}
\hline & R. championiae & R. farrerae & $R$. hongkongense & R. moulmainense & R. simiarum & $R$. simsii \\
\hline & & & Day & & & \\
\hline Hours of observation & 22.7 & 13.7 & 12.7 & 10.7 & 13.3 & 16.7 \\
\hline $\begin{array}{l}\text { Mean number of flowers } \\
\text { under observation }\end{array}$ & 115 & 129 & 193 & 172 & 207 & 286 \\
\hline \multicolumn{7}{|l|}{ Hymenoptera } \\
\hline Apis cerana & 0.61 & 4.77 & 3.68 & 8.51 & 0.39 & 0.43 \\
\hline Unknown bee & 0.64 & 0.13 & 0.00 & 1.91 & 0.00 & 0.00 \\
\hline Xylocopa spp. & 2.64 & 0.00 & 0.52 & 0.75 & 1.79 & 0.01 \\
\hline Bombus eximius & 1.64 & 0.39 & 0.87 & 1.41 & 2.33 & 0.34 \\
\hline Wasps & 0.07 & 0.09 & 0.36 & 0.48 & 0.34 & 0.00 \\
\hline \multicolumn{7}{|l|}{ Lepidoptera } \\
\hline Sphingidae & 0.47 & 0.00 & 0.36 & 0.16 & 0.00 & 0.00 \\
\hline Butterflies & 0.82 & 0.17 & 0.15 & 0.06 & 0.35 & 0.07 \\
\hline Coleoptera & 0.58 & 0.45 & 0.32 & 0.74 & 0.47 & 0.01 \\
\hline \multicolumn{7}{|l|}{ Diptera } \\
\hline Syrphidae & 0.25 & 0.83 & 0.02 & 0.26 & 0.28 & 0.02 \\
\hline Others & 0.00 & 0.00 & 0.00 & 0.00 & 0.27 & 0.00 \\
\hline Fork-tailed sunbird & 0.13 & 0.00 & 0.13 & 0.26 & $0.00 *$ & 0.00 \\
\hline Other insects & 0.00 & 0.00 & 0.02 & 0.00 & 0.00 & 0.05 \\
\hline Total visitors & 7.86 & 6.83 & 6.42 & 14.53 & 6.22 & 0.92 \\
\hline Total large bees & 4.28 & 0.39 & 1.39 & 2.16 & 4.13 & 0.35 \\
\hline \multicolumn{7}{|c|}{ Night } \\
\hline Hours of observation & 9.0 & 6.7 & 5.0 & 5.0 & 6.3 & 6.7 \\
\hline $\begin{array}{l}\text { Mean number of flowers } \\
\text { under observation }\end{array}$ & 115 & 140 & 259 & 152 & 307 & 411 \\
\hline Total visitors & 2.81 & 1.02 & 0.32 & 0.53 & 3.05 & 0.04 \\
\hline
\end{tabular}

${ }^{*}$ Two Fork-tailed Sunbirds were seen foraging on $R$. simiarum once in a casual observation.

tuid moths (including Apamea sodalis, Mythimna consangium, and Ophiusa triphaenoides) (Table 2). Other insects, including beetles and crickets, were also occasionally seen. These nocturnal visitors rarely contacted the anthers or stigma, except for some hawkmoths, which occasionally contacted the anthers and stigma of $R$. championiae and $R$. moulmainense.

Visitation rates were low in all species during the study period, and would undoubtedly have been lower if observations had been made under wet or windy conditions, when only Bombus is active. Rhododendron simsii flowers had the lowest daytime visitation rate, with only one visitor per flower per $100 \mathrm{~h}$, whereas $R$. moulmainense had the highest, with 15 visitors per flower per $100 \mathrm{~h}$ (Table 2). Considering only the large bees (Bombus eximius and Xylocopa species), $R$. championiae was the most frequently visited species, while $R$. farrerae and $R$, simsii were least frequently visited. Rhododendron farrerae, $R$. hongkongense, and $R$. moulmainense were mainly visited by Apis cerana, while $R$. simiarum and $R$. championiae were mainly visited by large bees. Both Apis cerana and large bees were equally frequent for $R$. simsii.

\section{Breeding system}

All six species produced very few or no seeds after handselfing (Tr. S) while seed set was high in the hand-crossing treatment (Tr. C) (Table 3). The differences between the two treatments were significant (Dunn's test; $p<0.05$ ) in all species except $R$. farrerae. The self-compatibility index (SCI) was low in all species, ranging from 0.00 to 0.18 (Table 3 ).
Although $R$. farrerae, $R$. hongkongense, $R$. simiarum, and $R$. simsii all showed a high percentage fruit set after hand selfing, comparable to that after hand crossing (Table 3), selfed fruits mostly contained very few or no seeds. Such empty fruits were also found occasionally among openpollinated plants. The low fruit and seed set in bagged treatments in these four species suggested there was no mechanism for self-pollination. Seed set per flower under open pollination was highest for $R$. championiae, while $R$. simiarum showed the highest percentage seed set (Table 3). Rhododendron farrerae and $R$. simsii had the lowest percentage seed set, seed set per flower, and seed set per plant under open-pollination, although they had a higher percentage of plants flowering than the other species (Tables 1 and 3).

\section{Seed characteristics}

Seeds of Rhododendron moulmainense and $R$. championiae have small, irregular, wing-like structures extending from the margin and both ends, while the other species showed no morphological adaptation for wind dispersal other than small size. Rhododendron simiarum had the heaviest seeds, and $R$. simsii had the lightest (Table 4). Seeds of $R$. simiarum had the highest wing loading and fell fastest among the six species, while those of $R$. moulmainense and $R$. championiae had the lowest wing loading and fell slowest. The mean terminal velocity for each species was significantly related to the square root of the mean wing loading $\left(r^{2}=0.782, p=\right.$ 0.016). Germination in light varied between species and years (Table 4). Seed germination rates were much lower in 
Table 3. Percentage fruit set and seed set per flower under different treatments in the pollination experiment, percentage seed set (mean number of seeds set divided by mean number of ovules and multiplied by a hundred) under open pollination, and self-compatibility index (SCI) for the six Rhododendron species.

\begin{tabular}{|c|c|c|c|c|c|c|}
\hline & R. championiae & R. farrerae & R. hongkongense & R. moulmainense & R. simiarum & R. simsii \\
\hline \multicolumn{7}{|c|}{$\%$ fruit set } \\
\hline Tr. $\mathrm{O}$ & $35.1(49) b^{*}$ & $16.2(58) b$ & $29.5(50) b$ & $15.6(58) b$ & $79.9(64) b c$ & $8.0(64) b c$ \\
\hline Tr. C & $92.9(15) a$ & $100.0(9) a$ & $100.0(16) a$ & $90.0(15) a$ & $97.4(15) a$ & $91.0(17) a$ \\
\hline Tr. S & $18.5(9) b c$ & $83.3(8) a$ & $60.9(23) b$ & $0.0(17) c$ & $88.5(14) a b$ & $47.0(16) b$ \\
\hline Tr. B & $1.5(17) c$ & $7.1(14) b$ & $4.2(20) c$ & $0.0(27) c$ & $13.3(15) c$ & $5.5(17) c$ \\
\hline \multicolumn{7}{|c|}{ Seed set per flower } \\
\hline Tr. O & $134.6(20) a^{*}$ & $1.9(18) b c$ & $106.9(28) b$ & $89.8(19) a$ & $95.6(41) b$ & $2.0(37) b$ \\
\hline Tr. C & $752.0(5) a$ & $237.4(9) a$ & $471.6(6) a$ & $723.7(4) a$ & $276.2(7) a$ & $336.8(12) a$ \\
\hline Tr. $\mathrm{S}$ & $0.0(7) b$ & $42.8(6) a b$ & $49.8(13) b c$ & $0.0(17) b$ & $21.0(6) c$ & $15.9(13) b$ \\
\hline Tr. B & $0.0(16) b$ & $0.0(13) c$ & $0.0(18) c$ & $0.0(27) b$ & $0.7(14) c$ & $0.4(15) c$ \\
\hline \multicolumn{7}{|c|}{$\%$ seed set } \\
\hline Tr. $\mathrm{O}$ & $9.7(20) b^{\dagger}$ & $0.3(18) c$ & $13.2(28) b$ & $4.9(19) b c$ & $35.8(41) a$ & $0.2(37) c$ \\
\hline SCI & 0.00 & 0.18 & 0.11 & 0.00 & 0.08 & 0.05 \\
\hline
\end{tabular}

Note: Numbers in parentheses are numbers of experimental units used for Tr. C, $S$, and B, and numbers of plants for Tr. O.

*Treatments followed by the same letter(s) were not significantly different at $p=0.05$.

${ }^{+}$Species followed by the same letter(s) were not significantly different at $p=0.05$.

the dark than in light for all species, except for $R$. simiarum, which showed equally high germination rates in light and dark. After storage for more than 1 year, only $R$. championiae and $R$. moulmainense retained high seed viability.

\section{Discussion}

All six species of rhododendrons found in Hong Kong have large, colorful flowers with sucrose-dominated nectar. Although the flowers seem to be most effectively pollinated by large bees, they are visited by a diverse assemblage of visitors, including four orders of insects and one species of bird. They are all more or less self-sterile and produce tiny, wind-dispersed seeds. This is consistent with the low inbreeding coefficients $\left(F_{\text {IS }}\right)$ observed in a genetic study of the same populations ( $\mathrm{Ng} \mathrm{1999),} \mathrm{which} \mathrm{suggests} \mathrm{an} \mathrm{outcrossing}$ breeding system in all six species. However, the details of the reproductive biology vary greatly between species, with a more than 6-fold range of pollen/ovule ratios and seed weights, and a more than 10 -fold range of daily and total nectar production, total and large bee visits per hour, and seed production per flower under open pollination. Seed production per plant per season varied by more than two orders of magnitude.

Studies on the breeding systems of other Rhododendron species have shown that while some are self-sterile, like the species studied here (Yamaguchi 1980; Williams et al. 1984; Padrutt et al. 1992), three alpine and one tropical species are self-fertile (Yamaguchi 1980; Williams et al. 1991; Kudo 1993; Escaravage et al. 1997). Self-sterility in rhododendrons appears to be different from classical sporophytic or gametophytic self-incompatibility. In cultivation, self pollen tubes were not inhibited in the style and ovary in $R$. championiae and $R$. moulmainense (under the synonym $R$. ellipticum) and could cause fertilization as well as outcross pollen, suggesting a postzygotic mechanism for self-sterility
(Williams et al. 1984). Similar results were observed for Rhododendron prinophyllum (Padrutt et al. 1992). The presence of empty self-fruits and the high percentage fruit set in the selfing treatment in the other four species studied here also suggests that abortion of self-ovules is not expressed before initiation of fruit development. The available evidence, however, is insufficient to determine whether these six species are exhibiting postzygotic incompatibility or early acting inbreeding depression, which are difficult to distinguish from each other (Seavey and Bawa 1986; Sage et al. 1994). The presence of a small but variable amount of seed set after selfing in $R$. farrerae, $R$. hongkongense, $R$. simiarum, and $R$. simsii is, nevertheless, typical for inbreeding depression.

The pollen/ovule ratios of all the species in Hong Kong, except $R$. simiarum, are low for xenogamous plants and comparable to the ratios reported for autogamous angiosperms (Cruden 1977). The unusual method of pollen presentation, with apically porose anthers and strongly adhesive pollen tetrads, together with viscin threads, may allow efficient transfer of substantial loads to pollinators and reduce wastage, thus reducing the need for a large excess of pollen (Cruden and Jensen 1979; Koptur 1984; Vasek and Weng 1988; Neiland and Wilcock 1995). Cruden and Jensen (1979) have suggested such efficient transfer of pollen may be adaptive in species with large numbers of ovules. The Orchidaceae, Asclepiadaceae, and Onagraceae, where pollen is packaged as pollinia or linked into loose clumps, have even lower pollen/ovule ratios than the rhododendrons in this study.

The high genetic diversities and low inbreeding coefficients of all six species in the study area ( $\mathrm{Ng} \mathrm{1999)}$ suggest that the low seed set under open pollination is unlikely to be due to inbreeding depression. The high seed set for the hand-cross treatment also confirms the fecundity of the six species and suggests that, at least at the level of branches 
Table 4. Seed germination (\%) under light and dark conditions in 1996, 1998, and 1999, and the weight, cross-sectional area, wing loading, and terminal velocity of the seeds of the six species of rhododendron.

\begin{tabular}{|c|c|c|c|c|c|c|}
\hline & R. championiae & R. farrerae & $R$. hongkongense & R. moulmainense & R. simiarum & R. simsii \\
\hline \multicolumn{7}{|l|}{ Seed germination } \\
\hline \multicolumn{7}{|l|}{ Light } \\
\hline 1996 & $27(301)$ & $8(300)$ & $40(300)$ & $65(300)$ & $65(150)$ & $20(294)$ \\
\hline 1998 & $74(50)$ & $26(50)$ & $44(50)$ & $8(66)$ & $70(50)$ & $52(50)$ \\
\hline 1999 & $63(81)$ & $5(82)$ & $14(81)$ & $90(81)$ & $0(76)$ & $14(91)$ \\
\hline \multicolumn{7}{|l|}{ Dark } \\
\hline 1998 & $26(50)$ & $6(50)$ & $2(50)$ & $27(67)$ & $70(66)$ & $34(50)$ \\
\hline 1999 & $5(86)$ & $1(75)$ & $1(81)$ & $1(81)$ & $3(75)$ & $17(90)$ \\
\hline Seed weight (mg) & $0.13(0.01)$ & $0.11(0.01)$ & $0.12(0.01)$ & $0.12(0.01)$ & $0.45(0.02)$ & $0.07(0.00)$ \\
\hline Cross-section area $\left(\mathrm{mm}^{2}\right)$ & $1.99(0.20)$ & $0.88(0.04)$ & $0.67(0.03)$ & $1.69(0.17)$ & $2.12(0.10)$ & $0.73(0.04)$ \\
\hline (Wing loading) $)^{1 / 2}\left(\mathrm{mg} \cdot \mathrm{cm}^{-1} \cdot \mathrm{s}^{-2}\right)^{1 / 2}$ & 82.4 & 111.5 & 133.5 & 87.6 & 145.6 & 96 \\
\hline Terminal velocity $\left(\mathrm{m} \cdot \mathrm{s}^{-1}\right)$ & $1.28(0.06)$ & $2.01(0.04)$ & $1.79(0.06)$ & $1.08(0.02)$ & $2.82(0.09)$ & $1.56(0.05)$ \\
\hline
\end{tabular}

Note: Values in parentheses are sample sizes for the percentage seed germination and standard errors for the other seed characteristics.

and inflorescences, seed set is limited by outcross pollen supply. The significant correlation across species between the mean large-bee visitation rate and the mean seed set under open pollination $(r=0.82, p<0.05)$ suggests that this, in turn, may be a result of pollinator limitation (Burd 1994; Larson and Barrett 1999). This is not surprising in view of the very low visitation rates by potential pollinators, which imply that, even in good weather, most flowers, particularly of $R$. farrerae and $R$. simsii, will have no large-bee visits at all during their 3- to 6-day life spans. Even hand-selfing produced more seeds than open pollination in $R$. farrerae and $R$. simsii, showing that the low seed set is not simply the result of geitonogamy (Harder and Barrett 1995). The observations reported here are from 2 consecutive years and are consistent with casual observations from 1995 to 1999 at other sites in Hong Kong, so they are unlikely to be an aberration. The total bee visitation rates are comparable, however, to those reported for Rhododendron aureum in Japan (five bees per flower per $100 \mathrm{~h}$; Kudo 1993) and Kalmia latifolia (Ericaceae) in North America (seven bees; Real and Rathcke 1991), where pollinator limitation was also suggested to cause low fruit set. Differences between species in the large-bee visitation rate probably reflect a preference for flowers with high nectar rewards (Real and Rathcke 1991), as suggested by the significant correlation across species between the mean large-bee visitation rate and mean daily nectar production $(r=0.82, p<0.05)$.

Field observations suggested that large Xylocopa and Bombus bees are the most effective pollinators for all six species. Dependence on large bees is a potential problem, however, for plants flowering early in the year in Hong Kong, as Xylocopa species, the most common large bees, do not usually fly at temperatures below $22-24^{\circ} \mathrm{C}$ and are not reliably available as pollinators until mid-April. Xylocopa bees also seem to find the nectar rewards in $R$. farrerae and $R$. simsii too small to be attractive and were very rarely seen visiting them. Bombus eximius, in contrast, flies throughout the flowering season and visited all six species, but is absent from much of Hong Kong ( $\mathrm{Ng}$ and Corlett 1997) where other rhododendron populations are found. Moreover, there were no records of bumblebees in Hong Kong before 1996 and it is possible that they have only become established re- cently. It therefore seems likely that Apis cerana, which is ubiquitous in Hong Kong and active on warm days ( $>12$ $14^{\circ} \mathrm{C}$ ) all winter, is responsible for much of the pollination before April at sites where Bombus is absent, and later on in the species that are unattractive to Xylocopa.

Despite their small sizes, the wing loading of the seeds of the six Rhododendron species are within the range of much larger, wind-dispersed tree diaspores (Green 1980; Augspurger 1986; Sinha and Davidar 1992). Their terminal velocities for a given wing loading are similar to those of neotropical tree diaspores with no special adaptations to produce lift (i.e., "floaters," Augspurger 1986). Mean dispersal distances are inversely proportional to terminal velocity (Greene and Johnson 1995; Murren and Ellison 1998). Using the long distance dispersal model of Greene and Johnson (1995) and the mean monthly wind speed of $6.53 \mathrm{~m} / \mathrm{s}$ recorded between October and December at a hill-top site in Hong Kong (Climatology Section, Hong Kong Observatory), it can be estimated that $0.01 \%$ of rhododendron seeds released from $2 \mathrm{~m}$ above ground level will be dispersed at least $30-80 \mathrm{~m}$ from the source. This will be a minimum figure, since field observations suggest that seeds are only removed from the fruits by exceptionally strong gusts (which reach $24 \mathrm{~m} / \mathrm{s}$ at the same meteorological site) and most rhododendron plants in Hong Kong occur on exposed ridge tops, where seeds are released into turbulent air. However, these estimates compare with foraging ranges of at least $3-$ $10 \mathrm{~km}$ for the large bee pollinators (Roubik 1989), which suggests that pollen may be more important than seeds in gene flow for these species.

The light requirement for seed germination, except in $R$. simiarum, is consistent with field observations of an almost complete absence of seedlings in established populations, as has been reported in other rhododendron species (Plocher and Carvell 1987; Pornon and Doche 1995; Pornon and Escaravage 1999). Seedlings of $R$. farrerae, $R$. championii, and $R$. moulmainense were only found in small numbers in litter-free, open sites, while no seedlings at all were found for $R$. hongkongensis or $R$. simsii. For these five species, successful establishment seems to be rare and is probably episodic. Seedlings of $R$. simiarum, in contrast, were abundant in shaded, but litter-free, microsites. This species 
also has the largest seeds, with the highest wing loading and terminal velocity, and lowest ovule number, suggesting a somewhat different regenerative strategy.

Contrary to initial expectations, the common species are producing far fewer seeds per plant than the rare species, which in turn seems to reflect the very low nectar production and consequent low large-bee visitation rates in these two species. Furthermore, seedlings were rarely or never observed in all species, except the relatively rare $R$. simiarum. Not only does the reproductive biology not explain the observed patterns of relative abundance but it does not seem compatible with the obvious success of $R$. simsii, in particular, in recent, anthropogenic habitats. We have no reason to believe that average conditions for seed production and seedling establishment have changed significantly over recent decades, which suggests that successful recruitment must be patchy and episodic, and that established individuals of even the smallest species must be long-lived. The fact that the rare species are largely confined to naturally fire-free sites suggests that fire intolerance at the seedling or adult stage limits their distribution and abundance in Hong Kong.

\section{Acknowledgments}

The authors thank Dr. Lawrence Ramsden and Vicky W.Y. Lam for analyzing the nectar by HPLC, Laura M.Y. Wong for help in the field and laboratory, Roger Kendrick and Clive Lau for identifying insects, and two anonymous reviewers for their helpful comments. This research was supported by a postgraduate studentship from the University of Hong Kong.

\section{References}

Augspurger, C.K. 1986. Morphology and dispersal potential of wind-dispersed diaspores of Neotropical trees. Am. J. Bot. 73: 353-363.

Buchmann, S.L. 1983. Buzz pollination in angiosperms. In Handbook of experimental pollination biology. Edited by C.E. Jones and R.J. Little. Van Nostrand Reinhold, New York. pp. 73-113.

Burd, M. 1994. Bateman's principle and plant reproduction: the role of pollen limitation in fruit and seed set. Bot. Rev. 60: 83-111.

Chamberlain, D., Hyam, R., Argent, G., Fairweather, G., and Walter, K.S. 1996. The genus Rhododendron: its classification and synonymy. Royal Botanic Garden Edinburgh, Edinburgh, U.K.

Cooper, S.D., and McGraw, J.B. 1988. Constraints on reproductive potential at the level of the shoot module in three ericaceous shrubs. Funct. Ecol. 2: 97-108.

Cross, J.R. 1981. The establishment of Rhododendron ponticum in the Killarney Oakwoods, S.W. Ireland. J. Ecol. 69: 807-824.

Cruden, R.W. 1977. Pollen-ovule ratios: a conservative indicator of breeding systems in flowering plants. Evolution, 31: 32-46.

Cruden, R.W., and Jensen, K.G. 1979. Viscin threads, pollination efficiency and low pollen-ovule ratios. Am. J. Bot. 66: 875-879.

Dudgeon, D., and Corlett, R.T. 1994. Hills and streams: an ecology of Hong Kong. Hong Kong University Press, Hong Kong.

Escaravage, N., Pornon, A., Doche, B., and Till-Bottraud, I. 1997. Breeding system in an alpine species: Rhododendron ferrugineum L. (Ericaceae) in the French northern Alps. Can. J. Bot. 75: 736-743.

Green, D.S. 1980. The terminal velocity and dispersal of spinning samaras. Am. J. Bot. 67: 1218-1224.
Greene, D.F., and Johnson, E.A. 1995. Long-distance wind dispersal of tree seeds. Can. J. Bot. 73: 1036-1045.

Harder, L.D., and Barrett, S.C.H. 1995. Matting cost of large floral displays in hermaphrodite plants. Nature (London), 373: $512-515$.

King, M.J., and Buchmann, S.L. 1995. Bumble bee-initiated vibration release mechanism of Rhododendron pollen. Am. J. Bot. 82: $1407-1411$.

Kjellsson, G., Rasmussen, F.N., and Dupuy, D. 1985. Pollination of Dendrobium infundibulum, Cymbidium insigne (Orchidaceae) and Rhododendron lyi (Ericaceae) by Bombus eximius (Apidae) in Thailand: a possible case of floral mimicry. J. Trop. Ecol. 1: 289-302.

Kohyama, T., and Grubb, P.J. 1994. Below- and above-ground allometries of shade-tolerant seedlings in a Japanese warmtemperate rain forest. Funct. Ecol. 8: 229-236.

Koptur, S. 1984. Outcrossing and pollinator limitation of fruit set: breeding systems of Neotropical Inga trees (Fabaceae: Mimosoideae). Evolution, 38: 1130-1143.

Kornerup, A., and Wanscher, J.H. 1978. Methuen handbook of colour. 3rd ed. Methuen, London, U.K.

Kudo, G. 1993. Relationship between flowering time and fruit set of the entomophilous alpine shrub, Rhododendron aureum (Ericaceae), inhabiting snow patches. Am. J. Bot. 80: 1300-1304.

Kunin, W.E., and Gaston, K.J. 1993. The biology of rarity: patterns, causes, and consequences. Trends Ecol. Evol. 8: 298-301.

Kunin, W.E., and Shmida, A. 1997. Plant reproductive traits as a function of local, regional, and global abundance. Conserv. Biol. 11: $183-192$.

Larson, B.M.H., and Barrett, S.C.H. 1999. The ecology of pollen limitation in buzz-pollinated Rhexia viriginica (Melastomataceae). J. Ecol. 87: 371-381.

Lloyd, D.G., and Schoen, D.J. 1992. Self- and cross-fertilization in plants. I. Functional dimensions. Int. J. Plant Sci. 153: 358-369.

Murren, C.J., and Ellison, A.M. 1998. Seed dispersal characteristics of Brassavola nodosa (Orchidaceae). Am. J. Bot. 85: 675-680.

Neiland, M.R.M., and Wilcock, C.C. 1995. Maximization of reproductive success by European Orchidaceae under conditions of infrequent pollination. Protoplasma, 187: 39-48.

Ng, S.C. 1999. Hong Kong's rhododendrons: ecology, population genetics and conservation. Ph.D. thesis, University of Hong Kong, Hong Kong, China.

$\mathrm{Ng}$, S.C., and Corlett, R.T. 1997. Bumblebees (Bombus eximius: Apidae, Bombinae) in Hong Kong. Vol. 21. Memoirs of the Hong Kong Natural History Society, Hong Kong. pp. 69-126.

Padrutt, J., Pellett, H., and Ascher, P. 1992. Postpollination reproductive biology of Rhododendron prinophyllum (Small) Millais. J. Am. Soc. Hortic. Sci. 117: 656-662.

Plocher, A.E., and Carvell, K.L. 1987. Population dynamics of rosebay rhododendron thickets in the southern Appalachians (USA). Bull. Torrey Bot. Club, 114: 121-126.

Pornon, A., and Doche, B. 1995. Age structure and dynamics of Rhododendron ferrugineum L. populations in the northwestern French Alps. J. Veg. Sci. 6: 265-272.

Pornon, A., and Escaravage, N. 1999. Genotypic structure in clonal Rhododendron ferrugineum L. (Ericaceae) populations: origin and maintenance. Plant Ecol. 141: 145-150.

Pornon, A., Escaravage, N., Doche, B., and Till-Bottraud, I. 1997. Variation of reproductive traits in Rhododendron ferrugineum $\mathrm{L}$. (Ericaceae) populations along a successional gradient. Plant Ecol. 130: 1-11.

Real, L.A., and Rathcke, B.J. 1991. Individual variation in nectar production and its effect on fitness in Kalmia latifolia. Ecology, 72: $149-155$. 
Roubik, D.W. 1989. Ecology and natural history of tropical bees. Cambridge University Press, Cambridge, U.K.

Sage, T.L., Bertin, R.I., and Williams, E.G. 1994. Ovarian and other late-acting self-incompatibility systems. In Genetic control of self-incompatibility and reproductive development in flowering plants. Edited by E.G. Williams, A.E. Clarke, and R.B. Knox. Kluwer Academic, Dordrecht, Netherlands. pp. 116-140.

Seavey, S.R., and Bawa, K.S. 1986. Late-acting selfincompatibility in angiosperms. Bot. Rev. 52: 195-219.

Sinha, A., and Davidar, P. 1992. Seed dispersal ecology of a wind dispersed rain forest tree in the Western Ghats, India. Biotropica, 24: 519-526.

Stevens, P.F. 1976. The altitudinal and geographical distributions of flower types in Rhododendron section Vireya, especially in the Papuasian species, and their significance. Bot. J. Linn. Soc. 72: $1-33$.

Vasek, F.C., and Weng, V. 1988. Breeding systems of Clarkia sect. Phaeostoma (Onagraceae): I. Pollen-ovule ratios. Syst. Bot. 13:
336-350.

Williams, E.G., Kaul, V., Rouse, J.L., and Knox, R.B. 1984. Apparent self-incompatibility in Rhododendron ellipticum, $R$. championiae and $R$. amamiense: a post-zygotic mechanism. Incompat. Newslett. 16: 10-11.

Williams, E.G., Rouse, J.L., Kaul, V., and Knox, R.B. 1991. Reproductive timetable for the tropical Vireya rhododendron, $R$. macgregoriae. Sex. Plant Reprod. 4: 155-165.

Yamaguchi, S. 1980. Field tests of self-incompatibility in Rhododendron kiushianum. Incompat. Newslett. 12: 16-23.

Yumoto, T. 1987. Pollination systems in a warm temperate evergreen broad-leaved forest on Yaku Island. Ecol. Res. 2: 133-145.

Yumoto, T. 1988. Pollination systems in a cool temperate mixed coniferous and broad-leaved forest zone of Yakushima Island. Ecol. Res. 3: 117-129.

Zhuang, X.Y., and Corlett, R.T. 1997. Forest and forest succession in Hong Kong, China. J. Trop. Ecol. 13: 857-866. 